\title{
Electrocoagulation of model wastewater using aluminum electrodes
}

\author{
Smoczyński Lech*, Muńska Kamilla Teresa, Pierożyński Bogusław, Kosobucka Marta \\ University of Warmia and Mazury in Olsztyn, Department of Chemistry, Faculty of Environmental Management and Agriculture, \\ Plac Łódzki 4, 10-957 Olsztyn, Poland \\ Corresponding author: e-mail: lechs@uwm.edu.pl
}

\begin{abstract}
Electrocoagulation makes an alternative method to chemical coagulation. This paper presents the results obtained during the electrocoagulation of the model wastewater using aluminum electrodes. The wastewater was treated by means of chronopotentiometric electrocoagulation process in a static system, at the constant current $\mathrm{I}=0.3 \mathrm{~A}$; therefore higher doses of electrocoagulant required longer electrocoagulation time. Changes in zeta potential, $\mathrm{pH}$, turbidity, chemical oxygen demand (COD), suspended solids and total phosphorus concentrations in the treated wastewater were determined. A new method for determining the optimal dosage of the aluminum electrocoagulant was proposed through application of the third degree polynomial function rather than the parabolic equation. An increase in the electrocoagulant dose raised the share of sweep flocculation in the studied treatment process, resulting in the effective removal over $90 \%$ of phosphorus compounds from the system.
\end{abstract}

Keywords: model wastewater, dose of aluminum electrocoagulant.

\section{INTRODUCTION}

Wastewater is commonly treated with the involvement of mechanical and biological methods. Their effectiveness may be limited; therefore, supplementary treatment methods (mostly chemical) are often employed. One of such methods involves chemical coagulation, which supports the biological treatment of wastewater. Chemical coagulation is used to remove excess phosphorus compounds from industrial and municipal wastewater. The results generated by treatment models and simulations may significantly expand knowledge about the coagulation process ${ }^{1-3}$.

Electrocoagulation is an alternative method to chemical coagulation in the treatment of water and wastewater. Electrocoagulation methods generally involve iron or aluminum anodes that undergo electrolytic dissolution. Iron and aluminum ions are introduced into the processed water or wastewater where they act as electrocoagulants. Destabilization of the wastewater colloids, aggregation and flocculation are the main stages of the process. In the process of oxygen cathodic depolarization, introduction of coagulating $\mathrm{Al}^{3+}$ ions increases the system's $\mathrm{pH}$, whereas the conventional chemical coagulation always lowers $\mathrm{pH}$, due to the hydrolysis of $\mathrm{Al}^{3+}$ cations ${ }^{3-5}$. For the chemically coagulated and electrocoagulated wastewater, $\mathrm{Al}^{3+}$ cations create positively charged micelles: $\left\{\mathrm{Al}(\mathrm{OH})_{3}\right\}$ that act as colloidal sorbents for wastewater pollutants, such as suspended solids, phosphorus compounds and substances responsible for the COD load. Various authors have analyzed the electrolytic treatment of sewage ${ }^{6}$, effluents produced by textile and dyestuff industry ${ }^{7}$, pulp and paper ${ }^{\mathbf{8}, 9}$ or dairy ${ }^{\mathbf{1 0}}$. For the markets that are characterized by cheap energy and high cost of chemicals delivery, electrocoagulation poses a vital alternative to chemical coagulation, since aluminum electrodes are around ten times as light as coagulating substances. In addition electrocoagulation requires simple equipment and is easy to operate.

The experiment described in this study supported the development of a new method for the quantitative interpretation of the electrocoagulation process and the determination of the optimal electrocoagulant dose. It also made an attempt to explain the mechanism of treating model wastewater by electrocoagulation in a static system.

\section{EXPERIMENTAL}

The chronopotentiometric electrocoagulation process was carried out at constant current $(\mathrm{I}=$ const $)$ with the use of aluminum electrodes in a device shown in Fig. 1, below.

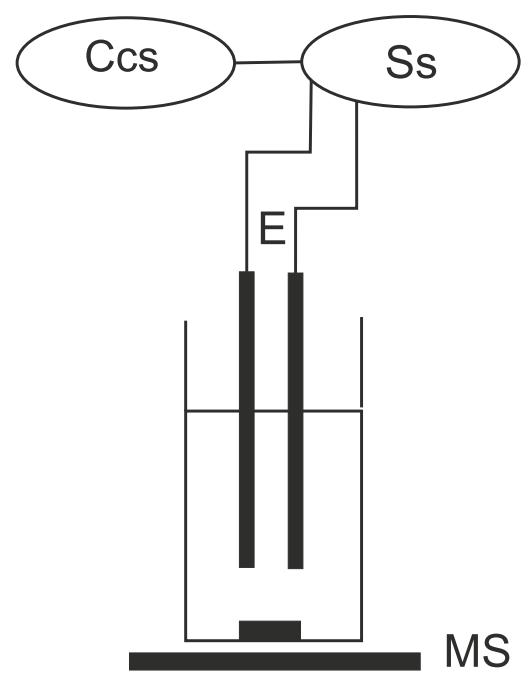

Figure 1. Diagram of electrocoagulation system: $M s-$ magnetic stirrer; E-electrodes; Ss - supply system; Ccs - computer control system

$100 \mathrm{~cm}^{3}$ of freshly prepared model wastewater with a phosphate buffer was poured into seven laboratory beakers. Saturated $\mathrm{NaCl}$ solution was added to each beaker in the quantities (usually 11 drops) that increased specific conductivity to $\kappa \approx 4 \mathrm{mS} \mathrm{cm}^{-1}$. The current was kept constant at $0.3 \mathrm{~A}$, so higher doses of electrocoagulant required longer electrocoagulation time. Electrocoagulation was performed with the use of two aluminum electrodes with dimensions: 100x10x1 mm and each containing $>99 \% \mathrm{Al}$ with a small addition of silicon. 
The electrodes were immersed at a depth of $5 \mathrm{~cm}$, with a precise spacing of $1 \mathrm{~cm}$, in $100 \mathrm{~cm}^{3}$ beakers containing model wastewater. Wastewater was continuously stirred at $30 \mathrm{rpm}$ by means of an electromagnetic stirrer. Treatment took place at the constant current of $0.3 \mathrm{~A}$ and means of resulting voltage (V) was recorded. Every 256 $\mathrm{s}$, the control system automatically changed the direction of the current flow between the electrodes in order to enable cathode self-cleaning ${ }^{11}$. A contaminated cathode was thus transformed into a soluble anode, and was purified through anodic dissolution process. The electrodes were weighed $(+/-0.0001 \mathrm{~g})$ before and after every use to gravimetrically control the actual consumption and to determine the applied electrocoagulant dose. Before being weighed, the electrodes were always carefully rinsed with distilled water and dried. The entire process was computer controlled. Both the hardware and software systems had been designed and built for the purpose of this experiment.

After the completion of electrolysis, the samples were collected from the supernatant layer, and the following wastewater parameters were determined after $30 \mathrm{~min}$ of sedimentation with the application of the commonly used standard HACH methods: $\mathrm{pH}$, COD, total phosphorus, turbidity and suspended solids concentrations. Zeta potential $(\zeta)$ of 5-100-fold diluted samples of treated wastewater was measured using the Malvern Zeta Sizer 3000. Electrocoagulation was performed in seven replications, where two highest and two lowest values were rejected. The remaining three values were used to compute the mean value and the standard deviation parameters.

\section{RESULTS AND DISCUSSION}

Changes of the recorded voltage for the constant current $(\mathrm{I}=0.3 \mathrm{~A})$ experiments were registered over time $t$. The average values of function $\mathrm{V}=\mathrm{f}(\mathrm{t})$ are shown in Fig. 2.

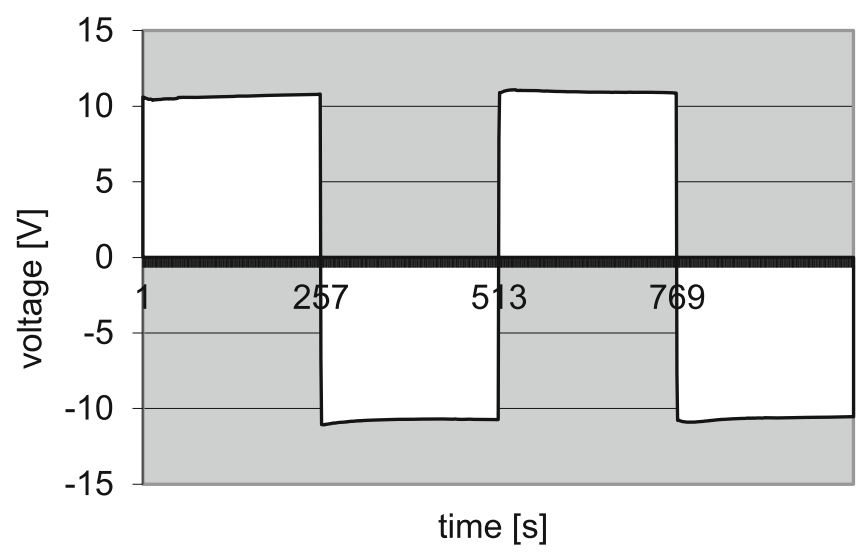

Figure 2. Changes in voltage over time at constant $\mathrm{I}=0.3 \mathrm{~A}$

The voltage changes observed during the electrocoagulation time (approximately $17 \mathrm{~min}$.) are presented in Fig. 2. A clear change in the current direction can be observed every $256 \mathrm{~s}$. This value guarantees electrode (cathode) self-cleaning and it minimizes polarization losses; therefore, it was adopted as the optimum parameter for electrocoagulation in the model systems ${ }^{11}$. During the electrolysis, voltage did not exceed $\pm 11 \mathrm{~V}$ or was actually constant. In semi-technical and industrial tests investigating natural wastewater, the above data would help to determine all electrocoagulation parameters, including: electric power, power consumption, etc.

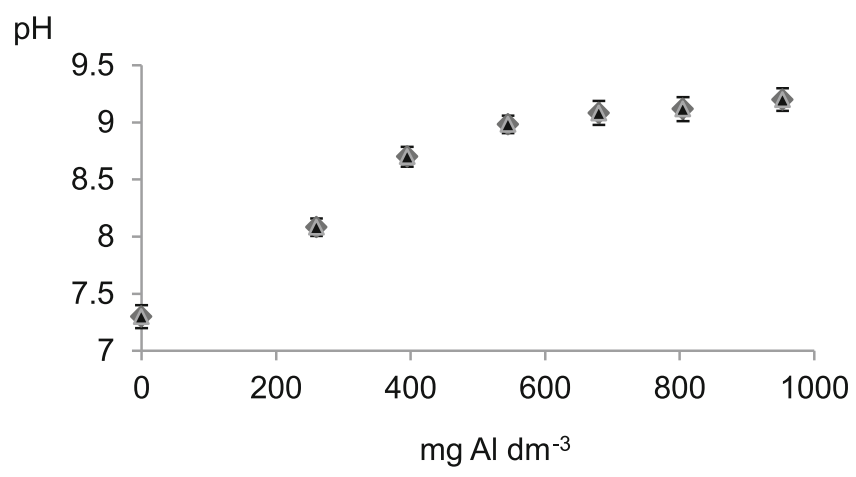

Figure 3. Changes in wastewater $\mathrm{pH}$

The increase in the $\mathrm{pH}$ of wastewater, treated with anodically dissolved $\mathrm{Al}$, results from reduction processes taking place at the cathode $(\mathrm{pH} \geq 7)$ :

$2 \mathrm{H}_{2} \mathrm{O}+2 \mathrm{e} \rightarrow \mathrm{H}_{2} \uparrow+2 \mathrm{OH}^{-}$

$\mathrm{O}_{2}$ (aq.) $+2 \mathrm{H}_{2} \mathrm{O}+4 \mathrm{e} \rightarrow 4 \mathrm{OH}^{-}$

The electrocoagulation process generates hydrogen and could involve a variety of anodic reactions, such as: $\mathrm{Al}-3 \mathrm{e} \rightarrow \mathrm{Al}^{3+}\left[\mathrm{Al}^{3+}+3 \mathrm{OH}^{-} \rightarrow \mathrm{Al}(\mathrm{OH})_{3}\right]$

Various authors have reported an increase in $\mathrm{pH}$ values during wastewater electrolysis ${ }^{12-14}$. A number of $\mathrm{Al}$ ions are formed, which are generally further transformed to amorphous $\mathrm{Al}(\mathrm{OH})_{3}$. Some of the following ions may be produced, depending on the $\mathrm{pH}$ of wastewater during electrocoagulation and chemical coagulation:

$\mathrm{Al}^{3+}, \quad \mathrm{Al}(\mathrm{OH})_{2}^{+}, \mathrm{Al}_{13}(\mathrm{OH})_{32}{ }^{7+}, \mathrm{Al}(\mathrm{OH})_{4}^{-}$,

These ions are usually further transformed to $\mathrm{Al}(\mathrm{OH})_{3}{ }^{15}$. The type of the resulting ions may significantly influence treatment effectiveness. It is believed that polymeric ions: $\mathrm{Al}_{3}(\mathrm{OH})_{4}{ }^{5+}$ are responsible for the destabilization of suspended solids and wastewater coagulation $^{16}$ at $\mathrm{pH}$ of 6.6 to 10.7 .

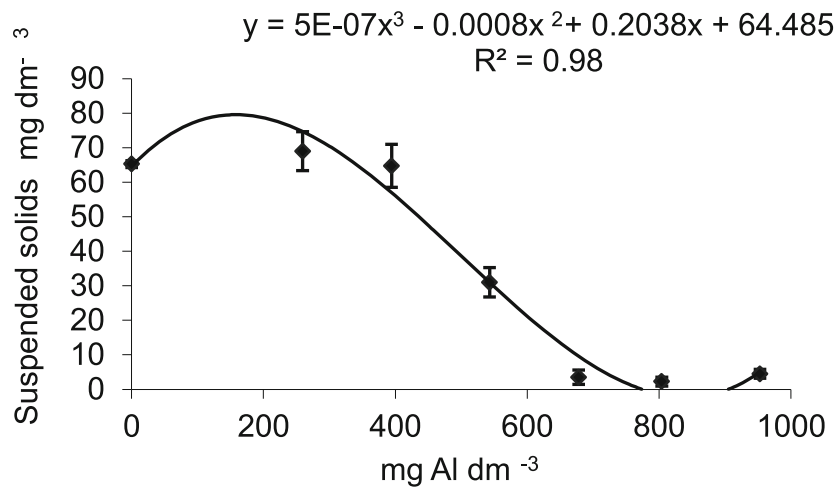

Figure 4. Removal of suspended solids (SS) from electrocoagulated wastewater

For the electrocoagulation involving aluminum electrodes, the two initial doses insignificantly lowered the analyzed wastewater parameters: SS, TU, P and COD. The application of the third dose of $543 \mathrm{mg} \mathrm{Al} \mathrm{dm}^{-3}$ resulted in a significant decrease of the suspended solids, see Fig. 4. A third degree polynomial method was applied to determine the optimal dosage in wastewater electrocoagulation, because this mathematical model provided optimum fitting parameters, including maximum 
of the determination coefficient $\left(\mathrm{R}^{2}\right)$ value. Faced with the option of calculating the optimal electrocoagulant dose between an abscissa of:

a) the bend point and

b) the minimum of the function,

we chose the latter method, which univocally indicated the maximum of wastewater purification.

The removal of suspended solids from the wastewater coagulated with the use of an aluminum electrocoagulant is presented in Fig. 4. The effectiveness of the applied mathematical model is demonstrated by the high value of the coefficient of determination $\mathrm{R}^{2}=0.98$. The dependency shown in Fig. 4 and the value of $\mathrm{R}^{2}$ indicate that the wastewater used is susceptible to electrolytic treatment. Such low standard deviation values suggest high reproducibility of the results. The most effective dose that removed nearly $97 \%$ of suspended solids was around $800 \mathrm{mg} \mathrm{Al} \mathrm{dm}^{-3}$. A much lower dose of $680 \mathrm{mg}$ $\mathrm{Al} \mathrm{dm}{ }^{-3}$ resulted in relatively close removal efficiency of approximately $95 \%$. An increase in electrocoagulant dose to $950 \mathrm{mg} \mathrm{Al} \mathrm{dm}{ }^{-3}$ only insignificantly increased suspended solids concentrations in treated wastewater. High electrocoagulant doses in excess of $800 \mathrm{mg} \mathrm{Al}$ $\mathrm{dm}^{-3}$ and $\mathrm{pH}$ values of treated wastewater exceeding 9.0 suggest, that after the sorption of suspended solids on colloidal micelles of aluminum hydroxide (latent and slow coagulation), sweep flocculation becomes the predominant process ${ }^{5}$. According to Holt et al. $2002^{16}$, at high pHs, suspended solids are no longer destabilized by aluminum cations and polycations, but by $\mathrm{Al}(\mathrm{OH})_{3}$. As a result, the wastewater treatment process is less likely to rely on the destabilization of the negatively charged wastewater colloids.

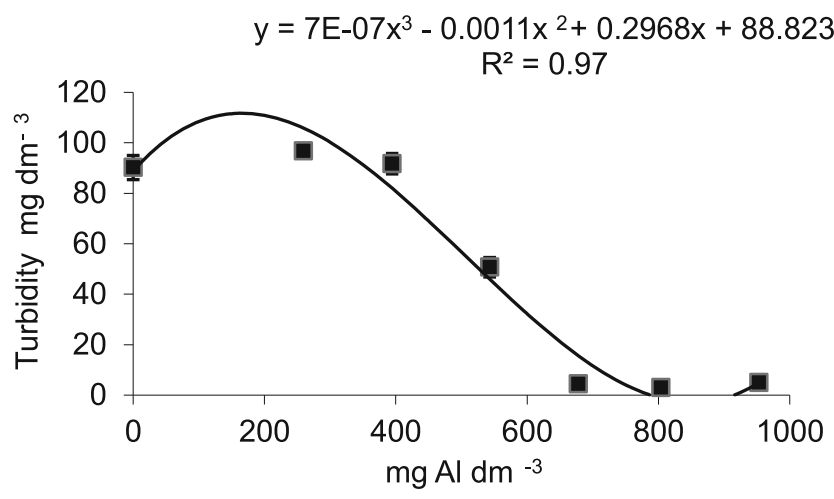

Figure 5. Removal of wastewater turbidity (TU)

The removal of turbidity from model wastewater coagulated with the use of aluminum electrocoagulant is presented in Fig. 5. The curve shows a high degree of similarity to the SS changes (Fig. 4). The observed similarity validates the control function, i.e. the correlation between the wastewater turbidity and the suspended solids. Similarly to the removal of the suspended solids, the most effective dose of around $800 \mathrm{mg} \mathrm{Al} \mathrm{dm}{ }^{-3}$ removed turbidity in nearly $97 \%$. The doses of 680 and $950 \mathrm{mg}$ $\mathrm{Al} \mathrm{dm}{ }^{-3}$ were nearly as effective, leading to $95 \%$ and 94\% turbidity removal, respectively. The low standard deviation values and a high coefficient of determination $\mathrm{R}^{2}=0.97$ indicate high quality of fit resulting from the application of the third degree polynomial mathematical function to the experimentally obtained data. This mathematical model is apparently not free of deficiencies and as such has a limited range of applications. Thus, for the highest doses of electrocoagulant, a computer-simulated trendline may actually cross an $\mathrm{X}$ axis. The above might imply that SS (Fig. 4) and TU (Fig. 5) become reduced by more than $100 \%$, which is physically impossible.

It can be assumed that the relatively high electrocoagulant doses were required for a complete turbidity removal, due to the high $\mathrm{pH}$ value of the treated wastewater. In fact treatment effectiveness is largely determined by the form of ions, which emerge as "primary" ions in the electrocoagulation system. The lowest dose increased $\mathrm{pH}$ to around 8.1 and a further increase in electrocoagulant doses raised $\mathrm{pH}$ to approximately 9 . At such high $\mathrm{pHs}$, a colloidal $\mathrm{Al}(\mathrm{OH})_{3}$ is predominant in the system and the main process during wastewater treatment is sorption on colloidal micelles of aluminum hydroxide, whereas the share of sweep electrocoagulation gradually increases at higher electrocoagulant doses ${ }^{5}$. The chemical coagulation process is completely different for wastewater with low pHs, where in addition to sorption, impurities are destabilized by positively charged monomeric and polymeric aluminum species ${ }^{17}$. At low $\mathrm{pH}$, pollutant destabilization is additionally enhanced by the presence of $\mathrm{H}^{+}$ions. Similarly to the removal of the suspended solids, an increase in electrocoagulant dose to $950 \mathrm{mg}$ $\mathrm{Al} \mathrm{dm}{ }^{-3}$ led to an insignificant rise in turbidity values. A further dose augmentation would probably inhibit the coagulation process, as well as, it could cause destabilization/peptization, leading to limited dissolution of the produced sludge.

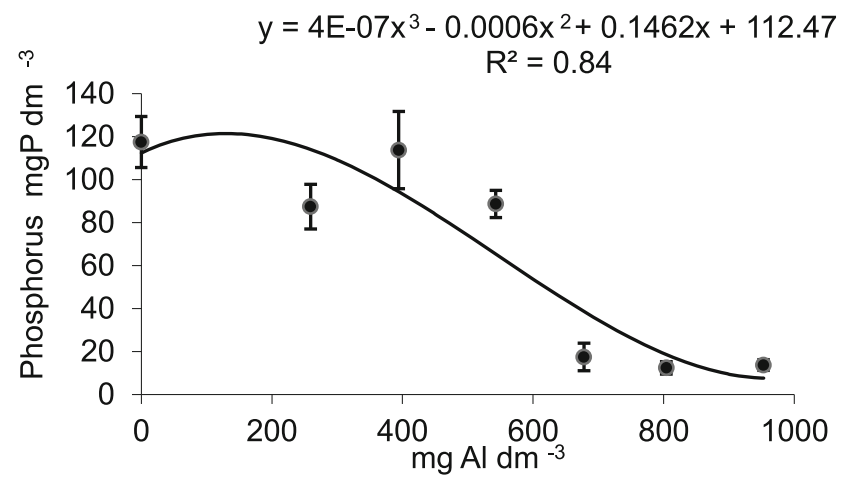

Figure 6. Removal of total phosphorus

The removal of phosphorus compounds from the model wastewater coagulated by means of aluminum electrocoagulant is presented in Fig. 6. In comparison with the previous charts, the above curve is characterized by a lower coefficient of determination $\mathrm{R}^{2}=0.84$. Similarly to the turbidity and the suspended solids removal, the last of the three applied doses resulted in comparable removal values with respect to phosphorus compounds. The most effective dose removed $89 \%$ phosphorus compounds from the treated wastewater.

The removal of the substances responsible for the COD from the model wastewater coagulated with aluminum electrocoagulant is presented in Fig. 7. Unlike the phosphorus removal curve, the COD curve is characterized by high values of coefficient of determination $\mathrm{R}^{2}=0.97$ and low standard deviation values. Once again, the above confirms the high repeatability and reproducibility of experimental results and the studied wastewater's susceptibility to electrolytic treatment. The most effective dose 
Table 1. Major results of the wastewater electrocoagulation

\begin{tabular}{|l|c|c|c|c|}
\hline Wastewater component & $\begin{array}{c}\text { Initial value } \\
\mathrm{mg} \mathrm{dm}^{-3}\end{array}$ & $\begin{array}{c}\text { Final value } \\
\mathrm{mg} \mathrm{dm}^{-3}\end{array}$ & $\begin{array}{c}\text { Removal } \\
\%\end{array}$ & $\begin{array}{c}\text { Optimal dose } \\
\mathrm{mg} \mathrm{Al} \mathrm{dm}^{-3}\end{array}$ \\
\hline Suspended solids & $70 \pm 5$ & 0 & 100 & 840 \\
\hline Turbidity & $95 \pm 5$ & 0 & 100 & 850 \\
\hline Total phosphorus & $110 \pm 10$ & 6.9 & 94 & 956 \\
\hline COD & $14500 \pm 500$ & 6950 & 53 & 860 \\
\hline
\end{tabular}

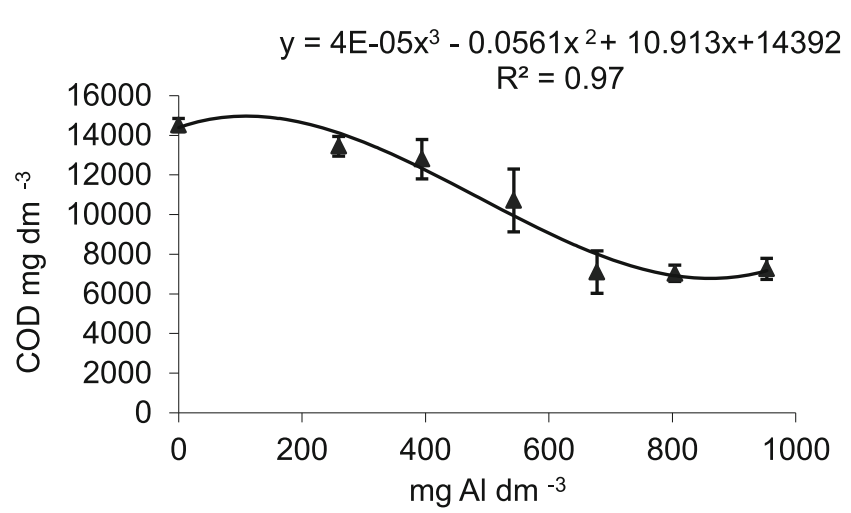

Figure 7. Removal of substances responsible for the COD

of around $800 \mathrm{mg} \mathrm{Al} \cdot \mathrm{dm}^{-3}$ removed $51 \%$ of substances responsible for the COD load. Electrocoagulant doses of 680 and $950 \mathrm{mg} \mathrm{Al} \mathrm{dm}^{-3}$ provided similar removal efficiency of $49 \%$ and $59 \%$, respectively.

Major results of the wastewater electrocoagulation were collected in table 1 . A minimum value of the third degree polynomial calculated for SS, TU, P and COD changes (see Figs. 4 through 7) indicated the following Al-electrocoagulant doses (a value of the abscissa) respectively: 840, 850, 965 and $860 \mathrm{mg} \mathrm{Al} \mathrm{dm}^{-3}$. The doses removed $100 \%$ of both SS and TU, 94\% of P and 53\% of COD. The changes in TU and SS values were well correlated. As previously observed ${ }^{\mathbf{1 1}}$, the initial small electrocoagulant dose (below $400 \mathrm{mg} \mathrm{dm}^{-3}$ ) appeared to be ineffective, because the specific value of the "threshold charge" can initiate and speed up the purification process only if larger aggregates form settleable flocs. High optimal doses of Al-electrocoagulant result from the simplicity of the electrocoagulation system used, which enabled weighing of the electrodes. Such high doses and relatively high $\mathrm{pH} \approx 9$ of treated wastewater suggest that sorption of suspended solids on colloidal micelles of aluminum hydroxide by sweep flocculation becomes the predominant process ${ }^{3,5}$. Thus, in spite of simple coagulation, the charge neutralization step plays a minimal role during the electrocoagulation process.

Fig. 8 presents the changes of zeta potential for the wastewater treated with Al-electrocoagulant. For the primary Al-electrocoagulant doses, a decrease in the absolute value of $\zeta$ in the Stern layer of the wastewater sol, as well as a reduction of the force of repulsion (responsible for the sol stability) was observed. It may imply that the neutralization of a colloidal charge can be a part of the process that somewhat contributes to the effectiveness of wastewater purification at the stage of latent (early) and slow electrocoagulation. Some flocs are formed in the system when latent and slow coagulation becomes fast and evident only when the conc. of $\mathrm{Al}>$ $400-500 \mathrm{mg} \mathrm{dm}^{-3}$. Further increase of Al-electrocoagu-

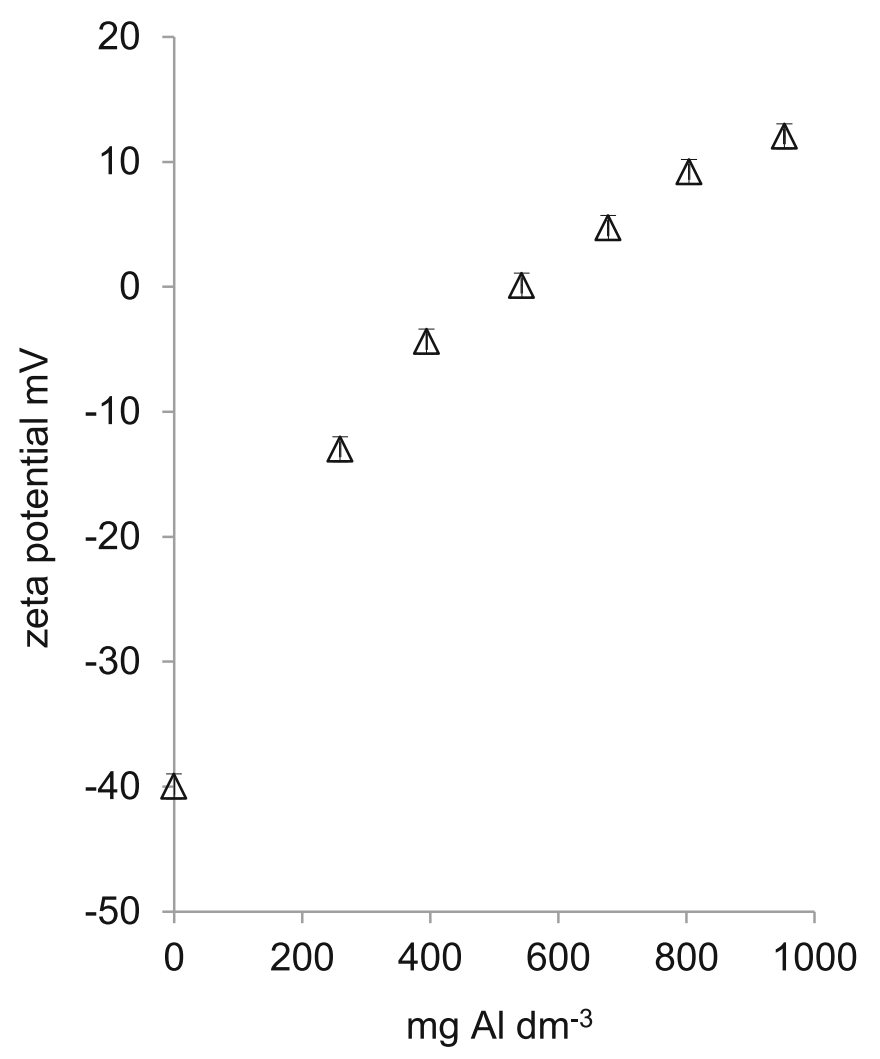

Figure 8. Changes of zeta potential for electrocoagulated wastewater

lant dose results in a positive shift of ca. $+12 \mathrm{mV}$ of the $\xi$-value for the treated wastewater, because the colloidal micelles of $\mathrm{Al}$ hydroxide with a minor positive charge may be present in the treated wastewater.

The observed changes in turbidity, suspended solids and phosphate compound concentrations indicated that experimental conditions supported the sweep coagulation mechanism ${ }^{5}$. Augmentation of $\mathrm{pH}$ during the treatment and high final $\mathrm{pH}$ prevented the generation of effective aluminum polycations that provided high treatment effectiveness at the stage of latent and slow coagulation. The aluminum species produced in the presence of excess electrocoagulant ions in alkaline environment supported:

a) sorption of substances responsible for the COD load on the surface of colloidal aluminum hydroxide,

b) sweeping of neutral, as well as the positively and negatively charged impurities, which remained in a direct contact with aluminum hydroxide flocs.

\section{CONCLUSIONS}

The investigated model wastewater was quite susceptible to electrocoagulation treatment. For all the cases turbidity removal values fully validated the results reported with respect to the suspended solids removal. 
The third degree polynomial method was useful to plot the curves showing changes in COD, total phosphorus concentrations, turbidity and the suspended solids concentrations during wastewater treatment and to calculate the relevant electrocoagulation doses. Every increase in the electrocoagulant dose raised the $\mathrm{pH}$ of the treated wastewater and minimized the probability of destabilization of the negatively charged wastewater colloids. The share of sweep coagulation in the electrochemical treatment process increased with higher doses of Aluminium electrocoagulant. The substances responsible for the COD load, as well as phosphates, were adsorbed by colloidal micelles of aluminum hydroxide. The results of zeta potential measurements indicated that the neutralization of electric charge of colloidal substances from the treated wastewater could be a part of the electrocoagulation mechanism.

\section{LITERATURE CITED}

1. Smoczyński, L., Bukowski, Z., Wardzyńska, R., Załęska-Chróst, N. \& Dłużyńska, K. (2009). Simulation of coagulation, flocculation and sedimentation. Water Environ. Res. 81 (4), 348-356. DOI:10.2175/106143008X357174.

2. Smoczyński, L., Mróz, P., Wardzyńska, R., Załęska-Chróst, B. \& Dłużyńska, K. (2009). Computer Simulation of Flocculation of Suspended Solids. Chem. Eng. J. 152, 146-150. DOI:10.1016/j.cej.2009.04.020.

3. Duan, J. \& Gregory, J. (2003). Coagulation by hydrolysing metal salts. J. Colloid and Interf. Sci. 100-102, 475-502. DOI:10.1016/S0001-8686(02)00067-2.

4. Kobya, M., Sentruk, E. \& Bayramoglu, M. (2006). Treatment of poultry slaughterhouse wastewaters by electrocoagulation. J. Hazard. Mater. B133, 172-176. DOI:10.1016/j. jhazmat.2005.10.007.

5. Armirtharajah, A. \& Mills, M.K. (1982). Rapid-mix design for mechanism of Alum coagulation. J. Am. Water Work As. 74 (4), 210-216.

6. Rodrigo, M.A., Canizares, P., Buitron, C. \& Saez, C. (2010). Electrochemical technologies for the regeneration of urban wastewater. Electrochim. Acta 55, 8160-8164. DOI:10.1016/j. electacta.2010.01.053.

7. Mollah, M.Y.A., Gomes, J.A.G., Das, K.K. \& Cocke, D.L. (2010). Electrochemical treatment of Orange II dye solution - Use of aluminum sacrificial electrodes and floc characterization. J. Hazard. Mater. 174, 851-858. DOI:10.1016/j. jhazmat.2009.09.131.

8. Kannadasan, T., Sivakumar, V., Ahmed Basha, C., Arun, V. P., Senthilkumar, K. \& Kannan, L. (2011). COD reduction studies of paper mill effluent using a batch recirculation electrochemical method. Pol. J. Chem. Tech. 13(3), 37-41. DOI 10.2478/v10026-011-0034-5.

9. Zaied, M. \& Bellakhal, N. (2009). Electrocoagulation treatment of black liquor from paper industry. J. Hazard. Mater. 163, 995-1000. DOI:10.1016/j.jhazmat.2008.07.115.

10. Tchamango, S., Nanseu-Njiki, C.P., Ngameni, E., Hadjiev, D. \& Darchen, A. (2010). Treatment of Dairy effluents by electrocoagulation using aluminium electrodes. Sci. Total Environ. 408, 947-952. DOI:10.1016/j.scitotenv.2009.10.02.

11. Groterud, O. \& Smoczyński, L. (1986). Phosphorus removal from water by electrolysis. Water Res. 20(5), 667-669. DOI:10.1016/0043-1354(86)90032-1.

12. Chen, X., Chen, G. \& Yue, P.L. (2000). Electrocoagulation and electroflotation of restaurant wastewaters. J. Environ. Eng. 126, 858-863. DOI:10.1061/(ASCE)0733-9372(2000)126:9(858)

13. Kobya, M. \& Delipinar, S. (2008). Treatment of the baker's yeast wastewater by electrocoagulation. J. Hazard. Mater. 154(1-3), 1133-1140. DOI:10.1016/j.jhazmat.2007.11.019.
14. Roa-Morales, G., Campos-Medina, E., Aguilera-Cotero, L., Bilyeu, B. \& Barrera-Diaz, C. (2006). Aluminum electrocoagulation with peroxide applied to wastewater from pasta and cookie process. Sep. Purif. Technol. 54(1), 124-129. DOI:10.1016/j.seppur.2006.08.025.

15. Gurses, A., Yalcin, M. \& Dogan, C. (2002). Electrocoagulation of some reactive dyes: a statistical investigation of some electrochemical variables. Waste Manage. 22, 491-499. DOI:10.1016/S0956-053X(02)00015-6.

16. Holt, P.K., Barton, G.W., Wark, M. \& Mitchell, C.A. (2002). Quantitative comparison between chemical dosing and electrocoagulation. Colloids Surf. 211, 233-248. DOI:10.1016/ S0927-7757(02)00285-6.

17. Jiang, J.Q. \& Lloyd, B. (2002). Progress in the development and use of ferrate(VI) salt as an oxidant and coagulant for water and wastewater treatment. Water Res. 36 (6), 1397-1408. DOI:10.1016/S0043-1354(01)00358-X. 